See Editorial page 47.

\section{Commentary: Hybrid palliation for hypoplastic left heart syndrome: Still feels like the tower of Babel}

\author{
Christian Pizarro, MD
}

Although the survival of children with hypoplastic left heart syndrome (HLHS) has exhibited a steady improvement over the last few decades, functional outcomes continue to present significant variability and several patient characteristics have been associated with worse outcomes. Based on its apparent "simplicity," the initial palliation with a hybrid approach has been revisited and embraced in many centers with different intents for a wide array of anatomy and in different clinical scenarios. As a consequence, outcomes following hybrid palliation are very difficult to analyze, being confounded by a lack of clarity about treatment goal, risk stratification, and, more importantly, the inclusion of patients with so-called "hypoplastic left heart complex" who would have undergone neonatal biventricular repair at many other institutions.

The article by Wilder and Caldarone ${ }^{1}$ provides an organized review of the current hybrid literature while analyzing the outcomes according to different intent and patient characteristics. Their suggested classification into Norwood alternative (the primary form of palliation), salvage procedure, deferred Norwood, bridge to transplantation, and bridge to univentricular-biventricular decision represent most of the scenarios in which a hybrid approach is considered and should be considered an essential component of outcome evaluation. It should be noted that patients in this last category, bridge to univentricular-biventricular

\footnotetext{
From the Nemours Cardiac Center, Alfred I. DuPont Hospital for Children, Wilmington, Del; and Departments of Surgery and Pediatrics, Sidney Kimmel School of Medicine, Thomas Jefferson University, Philadelphia, Pa.

Disclosures: The authors reported no conflicts of interest.

The Journal policy requires editors and reviewers to disclose conflicts of interest and to decline handling or reviewing manuscripts for which they may have a conflict of interest. The editors and reviewers of this article have no conflicts of interest.

Received for publication Sept 28, 2020; revisions received Sept 28, 2020; accepted for publication Oct 1, 2020; available ahead of print Oct 28, 2020.

Address for reprints: Christian Pizarro, MD, Nemours Cardiac Center, Alfred I. DuPont Hospital for Children, 1600 Rockland Rd, Wilmington, DE 19803 (E-mail: cpizarro@nemours.org).

JTCVS Open 2020;4:55

2666-2736

Copyright (C) 2020 The Authors. Published by Elsevier Inc. on behalf of The American Association for Thoracic Surgery. This is an open access article under the CC BY-NCND license (http://creativecommons.org/licenses/by-nc-nd/4.0/).

https://doi.org/10.1016/j.xjon.2020.10.003
}

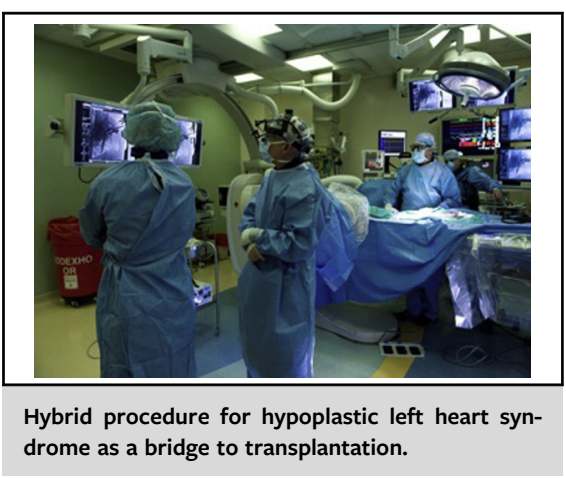

CENTRAL MESSAGE

Outcomes of hybrid palliation for

hypoplastic left heart syndrome

should be interpreted based on

treatment goal and patient

profile.

decision, is the most challenging group to analyze, because they might not necessarily have HLHS but may have some form of critical left ventricular outflow obstruction and commonly defer biventricular repair, often to mitigate the risk of a challenging neonatal repair, and are commonly associated with improved outcomes. A critical analysis of the published series is essential to understand the real outcomes of the hybrid intervention and be able to evaluate the merits of this approach in different circumstances. Undoubtedly, we have learned important lessons about what a hybrid palliation can offer. For example, although it optimizes hemodynamics and allows the recovery of end-organ dysfunction in those who present with a late diagnosis and shock, it will not eliminate the risk associated with chromosomal anomalies and genetic syndromes. The most coveted prize, of course, is the hope for a better neurodevelopmental outcome, yet that remains to be demonstrated.

As suggested by Wilder and Caldarone, some of these answers will not be available until data are risk-stratified and goals are clearly defined. In the meantime, it is incumbent on us to collect prospective data and join forces to elucidate the true merits and limitations of this novel form of management, which may still be considered a breakthrough in the management of HLHS.

\section{Reference}

1. Wilder TA, Caldarone CA. Apples to oranges: making sense of hybrid palliation for hypoplastic left heart syndrome. J Thorac Cardiovasc Surg. 2020;4:47-54. 